\title{
EFEITOS DO MANGANÊS SOBRE A SOJA CULTIVADA EM SOLO DE CERRADO DO TRIÂNGULO MINEIRO'
}

\author{
JOÃO ALBERTO DE OLIVEIRA JUNIOR ${ }^{2}$, EURÍPEDES MALAVOLTA ${ }^{3}$ e CLEUSA PEREIRA CABRAL ${ }^{4}$
}

\begin{abstract}
RESUMO - A deficiência de Mn em soja [Glycine max (L.) Merrill] e em outras culturas pode ser devida aos seus baixos teores no solo, ou à indisponibilidade do elemento induzida pela aplicação de calcário. O objetivo deste trabalho foi verificar a composição mineral da soja em relação à disponibilidade de Mn no solo. Em casa de vegetação foi conduzido um experimento utilizando um solo coletado no município de Patrocínio, MG, onde o café mostra sintomas de deficiência desse elemento. As doses de Mn foram: $0,10,50$ e $100 \mathrm{mg} \mathrm{kg}^{-1}$ e um tratamento adicional com aplicação foliar de 0,6\% de Mn e duas doses de calcário, ou seja: 0 e 2,7 t ha ${ }^{-1}$. Os teores de Mn na planta aumentaram com a dose de Mn no solo, e diminuíram com a aplicação de calcário. O menor teor de Mn encontrado nas folhas foi de $84 \mathrm{mg} \mathrm{kg}^{-1} \mathrm{na}$ dose 0 de Mn com calcário. O Mn provocou um aumento na produção de matéria seca e de vagens, em relação a ambas as doses de calcário. A calagem não induziu o aparecimento de sintomas de deficiência de Mn. A aplicação foliar de Mn foi eficiente em aumentar e manter a produção.
\end{abstract}

Termos para indexação: calagem, toxidez do solo, transporte de nutrientes, Glycine max, folhas.

\section{EFFECTS OF MANGANESE ON SOYBEAN GROWTH IN A CERRADO SOIL OF TRIÂNGULO MINEIRO, MG, BRAZIL}

\begin{abstract}
Manganese deficiency in soybean [Glycine $\max$ (L.) Merrill) and in other crops could be due to its low levels in the soil, or to its unavailability induced by liming. The objective of this research was to verify the soybean mineral composition in relation to Mn availability. An experiment was carried out in a greenhouse, using soil from Patrocínio, MG, Brazil, where the cultivated coffee shows symptoms of Mn deficiency. Mn was applied at the rates of zero, 10, 50 and $100 \mathrm{mg} \mathrm{kg}^{-1}$ with an additional treatment of $0.6 \%$ of foliar applied $\mathrm{Mn}$ and two rates of lime, namely: zero and $2.7 \mathrm{t} \mathrm{ha}^{-1}$. Mn concentration in the plant tissue was increased with the rate of lime application; liming, however, caused a Mn reduction. It must be pointed out that the lowest $\mathrm{Mn}$ level in the leaves was $84 \mathrm{mg} \mathrm{kg}^{-1}$, at the zero rate of $\mathrm{Mn}$ with lime. Mn ratio caused an increase both in dry matter and grain yield either in the presence and absence of lime. Liming did not induce any symptom of Mn deficiency in the leaves. Leaf applied Mn was efficient to raise and maintain soybean yield.
\end{abstract}

Index terms: liming, soil toxicity, nutrient transport, Glycine max, leaves.

\section{INTRODUÇÃO}

A toxidez de $\mathrm{Mn}$, geralmente associada à do $\mathrm{Al}$, é mais freqüente do que sua deficiência, em solos áci-

\footnotetext{
${ }^{1}$ Aceito para publicação em 28 de julho de 1999. Projeto financiado pela FAPESP.

${ }^{2}$ Eng. Agrôn., aluno de curso de doutorado, Centro de Energia Nuclear na Agricultura (CENA), Universidade de São Paulo (USP), Caixa Postal 96, CEP 13400-970 Piracicaba, SP. Bolsista da FAPESP. E-mail: jaolivei@ cena.usp.br

${ }^{3}$ Eng. Agrôn., Dr., Seção de Nutrição Mineral de Plantas, CENA, USP. E-mail: mala@ cena.usp.br

${ }^{4}$ Biól., Seção de Nutrição Mineral de Plantas, CENA, USP. E-mail: cpcabral@cena.usp.br
}

dos de regiões tropicais e subtropicais (Dechen et al., 1991); entretanto, altas doses de calcário e sua má incorporação têm contribuído para a deficiência do elemento (Tanaka et al., 1992). Teores de Mn nas folhas entre 10 e $20 \mathrm{mg} \mathrm{kg}^{-1}$ causam o aparecimento de sintomas de deficiência na cultura da soja. Tanaka \& Mascarenhas (1992) atribuíram aos teores de Mn nas folhas de soja uma correlação positiva entre a produtividade de grãos e o teor de óleo, e uma relação negativa com o teor de proteína. Sintomas de deficiência de Mn em caupi (Vigna sinensis (L.) (Endl)) foram observados por uma redução na área foliar e nas folhas novas com clorose internerval; com a acentuação dos sintomas, os folíolos caíram, e a porção 
apical do caule permaneceu do tipo fino e comprido, chegando a alcançar o florescimento com pequena produção de vagens (Malavolta et al., 1980). Malavolta et al. (1989) esclareceram, mediante a diagnose foliar, um caso de clorose internerval em folhas de mandioca (var. Branca de Santa Catarina) na região de Patrocínio, MG. Os sintomas se mostravam semelhantes aos de carência de $\mathrm{Zn}$, mas pela análise da composição mineral em folhas com e sem sintomas, observaram teores de Mn entre 12 e $27 \mathrm{mg} \mathrm{kg}^{-1}$, respectivamente, os quais se mostraram responsáveis pela anormalidade; aqueles autores também observaram maior acúmulo dos elementos Fe e Zn. Novais et al. (1989) observaram que plantas de soja com sintomas caracterizados por clorose internerval intensa de folhas inferiores e por meio de análises, encontraram teores de Mn total na parte aérea inferiores a $20 \mathrm{mg} \mathrm{kg}^{-1}$.

A aplicação de qualquer composto mangânico altamente solúvel pode ser usada para aumentar a disponibilidade de Mn para as plantas; contudo, aumentar dessa forma o teor de Mn trocável não é economicamente viável, pelo fato de $\mathrm{o} \mathrm{Mn}^{2+}$ oxidarse a $\mathrm{Mn}^{4+}$ e precipitar como óxido (Borkert, 1991). O mais importante fator que governa a disponibilidade do Mn para as plantas, nas condições normais, é a reação do solo, pois a absorção desse elemento decresce com a elevação do $\mathrm{pH}$, em decorrência da formação de hidróxidos e óxido de Mn de baixa solubilidade.

Este trabalho teve como objetivo verificar a composição mineral da soja em relação à disponibilidade de manganês no solo.

\section{MATERIAL E MÉTODOS}

O ensaio foi conduzido em casa de vegetação do Centro de Energia Nuclear na Agricultura (CENA/USP), em Piracicaba, SP, utilizando um Latossolo Vermelho-Amarelo álico de textura média, proveniente do município de Patrocínio, MG. O solo foi peneirado, homogeneizado, secado ao ar, passado em peneira com malha de $2 \mathrm{~mm}$ de abertura, e colocado em vasos de barro de dois litros. As características químicas originais deste solo são: $\mathrm{pH}\left(\mathrm{CaCl}_{2}\right), 3,8 ; \mathrm{MO}, 41 \mathrm{~g} \mathrm{~kg}^{-1} ; \mathrm{P}$ (resina) $=6 \mathrm{mg} \mathrm{dm}^{-3}$; $\mathrm{S}-\mathrm{SO}_{4}=28,83 \mathrm{mg} \mathrm{dm}^{-3} ; \mathrm{K}$ (resina) $=0,6 \mathrm{mmol}_{\mathrm{c}} \mathrm{dm}^{-3}$; $\mathrm{Ca}($ resina $)=4 \mathrm{mmol}_{\mathrm{c}} \mathrm{dm}^{-3} ; \mathrm{Mg}($ resina $)=1 \mathrm{mmol}_{\mathrm{c}} \mathrm{dm}^{-3}$; $\mathrm{Al}=10 \% ; \mathrm{H}+\mathrm{Al}=10,9 \% ; \mathrm{SB}=5,6 \% ; \mathrm{T}=11,5 \%$;
$\mathrm{V}=6 \% ; \mathrm{m}=65 \% ; \mathrm{B}$ (água quente) $=0,29 \mathrm{mg} \mathrm{dm}^{-3}$; $\mathrm{Cu}($ DTPA $)=0,65 \mathrm{mg} \mathrm{dm}^{-3} ; \mathrm{Fe}($ DTPA $)=136 \mathrm{mg} \mathrm{dm}^{-3}$; $\operatorname{Mn}($ DTPA $)=3,10 \mathrm{mg} \mathrm{dm}^{-3} ; \mathrm{Zn}($ DTPA $)=0,8 \mathrm{mg} \mathrm{dm}^{-3}$. A cultivar de soja utilizada foi a IAC-14, sensível à deficiência de Mn. O delineamento experimental foi o de blocos inteiramente casualizados, em esquema fatorial, com dez tratamentos (duas doses de calcário e cinco doses de $\mathrm{Mn}$ ), com quatro repetições. A calagem foi realizada para elevar a saturação em bases a 70\%, com aplicação de uma dose equivalente a $2,7 \mathrm{t} \mathrm{ha}^{-1}$. O solo foi incubado com o calcário, e após 15 dias foram feitos os tratamentos com Mn. As doses de Mn foram: 0, 10, 50 e $100 \mathrm{mg} \mathrm{kg}^{-1}$ e um tratamento adicional com o Mn fornecido via foliar a $0,6 \%$, em duas aplicações, com intervalo de duas semanas, a partir do estádio R1. A fonte de Mn, em todos os tratamentos, foi o $\mathrm{MnSO}_{4} \cdot \mathrm{H}_{2} \mathrm{O}$. Após a incubação, foram determinados os teores de Mn em DTPA em todos os tratamentos. Foram deixadas duas plantas por vaso. $\mathrm{O} \mathrm{N}\left(150 \mathrm{mg} \mathrm{L}^{-1}\right) \mathrm{e}$ o $\mathrm{K}\left(100 \mathrm{mg} \mathrm{L}^{-1}\right)$ foram parcelados em três doses iguais de 50 e $33 \mathrm{mg} \mathrm{L}^{-1}$, na incubação e nos estádios V7(R1) e V8 (R2).

No decorrer do experimento, o desenvolvimento das plantas foi acompanhado pelo aparecimento de sintomas de deficiência e toxidez de Mn e pelo estádio de desenvolvimento descrito por Costa \& Marchezan (1978). As folhas senescentes foram acondicionadas em sacos de papel, devidamente identificados, e no estádio V8-9 (R3-4) coletou-se o quarto trifólio a partir do ápice, num total de dois trifólios por vaso. Após a coleta, determinou-se o teor de todos os macronutrientes e dos micronutrientes $\mathrm{B}, \mathrm{Cu}, \mathrm{Fe}$, Mn e Zn. O preparo das amostras e as análises químicas do material vegetal foram realizados segundo os procedimentos descritos por Malavolta et al. (1997).

As características avaliadas por ocasião da colheita foram as seguintes: peso da matéria seca de raiz, caule e ramos, folhas, vagens e grãos. Foram realizadas análises de variância e o teste $\mathrm{F}$, e, quando necessário, aplicou-se o teste de Tukey a 5\% quanto à matéria seca total e à vagem. Quanto às doses de Mn, foram feitas análises de regressão polinomial, separando-se os tratamentos com e sem calcário, com relação a grãos e produção de matéria seca total. Foram estabelecidas correlações entre os teores de Mn na planta e o teor de outros elementos. Todos os testes e procedimentos estatísticos seguiram os procedimentos descritos por Pimentel-Gomes (1984), e o sistema utilizado nas análises foi o SAS (Statistical Analysis System).

\section{RESULTADOS E DISCUSSÃO}

A produção de matéria seca e de grãos foi significativamente superior $(\mathrm{P}<0,05)$ com a aplicação de 
$50 \mathrm{mg} \mathrm{kg}^{-1}$ de $\mathrm{Mn}$, tanto na presença quanto na ausência de calcário, e a aplicação foliar do Mn não diferiu da melhor dose de Mn aplicada via solo (Tabela 1). A Fig. 1 mostra o efeito das doses de Mn na produção de grãos e matéria seca em ambas as doses de calcário. Quando se toma por referência a testemunha (dose 0 ), observa-se que os maiores aumentos na produção foram obtidos com as doses de $10 \mathrm{e}$ $50 \mathrm{mg} \mathrm{kg}^{-1}$ de $\mathrm{Mn}$, tanto na presença como na ausência de calcário, enquanto a dose de $100 \mathrm{mg} \mathrm{kg}^{-1}$ sem calcário causou um efeito depressivo na produção de matéria seca e de grãos. Salcedo et al. (1979) obtiveram as melhores respostas com aplicações de 10 a $20 \mathrm{mg} \mathrm{kg}^{-1}$ de $\mathrm{Mn}$ no solo na forma de $\mathrm{MnSO}_{4}$. Para Abreu et al. (1995), em experimento conduzido em um LVA distrófico, textura média, deficiente em $\mathrm{Mn}$, o maior aumento na produção de matéria seca foi quando forneceram $40 \mathrm{mg} \mathrm{kg}^{-1}$ de $\mathrm{Mn}$, porém Rosolem et al. (1992) não obtiveram resposta significativa na produção de matéria seca de soja com aplicações de 0 a $120 \mathrm{mg} \mathrm{kg}^{-1}$ de Mn.

Os teores de manganês em DTPA encontrados no solo, com relação às doses $0,10,50$ e $100 \mathrm{mg} \mathrm{kg}^{-1}$ foram: $1,6 \mathrm{mg} \mathrm{dm}^{-3}, 3,55 \mathrm{mg} \mathrm{dm}^{-3}, 13,6 \mathrm{mg} \mathrm{dm}^{-3} \mathrm{e}$ $16,7 \mathrm{mg} \mathrm{dm}^{-3}$ para dose 0 de calcário, e $1,0 \mathrm{mg} \mathrm{dm}^{-3}$, $6,2 \mathrm{mg} \mathrm{dm}^{-3}, 18,8 \mathrm{mg} \mathrm{dm}^{-3} \mathrm{e} 25,3 \mathrm{mg} \mathrm{dm}^{-3}$ para a dose equivalente a $2,7 \mathrm{t} \mathrm{ha}^{-1}$ de calcário. Para uma adequada nutrição das plantas, o solo deve apresentar

TABELA 1. Efeito da aplicação de manganês e calcário (cal.) na produção de matéria seca (MS) e grãos de soja cultivada em solo de cerrado. Média de quatro plantas ${ }^{1}$.

\begin{tabular}{|c|c|c|}
\hline Tratamento & Grãos (g/vaso) & MS (g/vaso) \\
\hline Testemunha & $5,248 \mathrm{e}$ & $10,990 \mathrm{e}$ \\
\hline Calcário & $6,770 \mathrm{bcde}$ & $17,405 \mathrm{bc}$ \\
\hline $10 \mathrm{mg} \mathrm{kg}^{-1}$ de $\mathrm{Mn}$ & $6,743 \mathrm{bcde}$ & $12,588 \mathrm{de}$ \\
\hline $10 \mathrm{mg} \mathrm{kg}^{-1}$ de $\mathrm{Mn}+$ cal. & $8,595 \mathrm{a}$ & $20,088 \mathrm{ab}$ \\
\hline $50 \mathrm{mg} \mathrm{kg}^{-1}$ de $\mathrm{Mn}$ & $7,290 \mathrm{abcd}$ & $13,053 \mathrm{de}$ \\
\hline $50 \mathrm{mg} \mathrm{kg}^{-1}$ de $\mathrm{Mn}+\mathrm{cal}$ & $8,403 \mathrm{ab}$ & $18,253 b c$ \\
\hline $100 \mathrm{mg} \mathrm{kg}^{-1}$ de $\mathrm{Mn}$ & $6,285 \mathrm{cde}$ & $11,038 \mathrm{e}$ \\
\hline $100 \mathrm{mg} \mathrm{kg}^{-1}$ de $\mathrm{Mn}+$ cal. & $7,768 \mathrm{abc}$ & $15,800 \mathrm{~cd}$ \\
\hline Mn via foliar $(0,6 \%)$ & $6,015 \mathrm{cde}$ & $13,000 \mathrm{de}$ \\
\hline Mn via foliar $(0,6 \%)+$ cal. & $8,228 \mathrm{ab}$ & $19,755 \mathrm{ab}$ \\
\hline C.V. (\%) & 11,37 & 9,75 \\
\hline D.M.S. (5\%) & 1,77 & 3,37 \\
\hline
\end{tabular}

${ }^{1}$ Valores seguidos da mesma letra não diferem entre si a $5 \%$ de probabilidade pelo teste de Tukey. teores de Mn solúvel em água, trocável e facilmente redutível de 2 a $3 \mathrm{mg} \mathrm{kg}^{-1}, 0,2$ a $5 \mathrm{mg} \mathrm{kg}^{-1}$ e 25 a $65 \mathrm{mg} \mathrm{kg}^{-1}$, respectivamente (Tisdale et al., 1985). O Mn extraído pelo DTPA é considerado como parte do trocável mais o complexado. Os valores de Mn no solo extraído pelo DTPA estão abaixo do mencionado com relação a uma adequada nutrição das plantas da testemunha e do tratamento com calcário. Para Abreu et al. (1994), o DTPA não detectou a diminuição na disponibilidade do Mn causada pela calagem, e mostrou-se o mais eficiente em recuperar o Mn aplicado ao solo. O DTPA detectou as variações causadas pela calagem; a correlação entre o Mn das folhas e o Mn encontrado no solo pelo DTPA estão na Fig. 2.

Os efeitos favoráveis da aplicação de calcário foram maiores que o dano causado pela diminuição do teor de Mn, uma vez que o solo original possuía baixos valores de $\mathrm{pH}$. $\mathrm{O} \mathrm{pH}\left(\mathrm{CaCl}_{2}\right)$ inicial do solo usado era de 3,8 e de 5,4 e 4,5 após a incubação para os tratamentos com e sem calcário, respectivamente. Esses valores estão abaixo dos mencionados por Sims (1986), Novais et al. (1989) e Tanaka et al. (1992) para que ocorra a deficiência de Mn. Segundo os mesmos autores, a maior mudança na disponibilidade do $\mathrm{Mn}$ ocorre em valores de $\mathrm{pH}$ entre 4,0 e 6,0. No experimento, as mudanças de $\mathrm{pH}$ estiveram dentro desta variação; porém, apesar de ter sido reduzida a disponibilidade do elemento, não ocorreram sintomas de

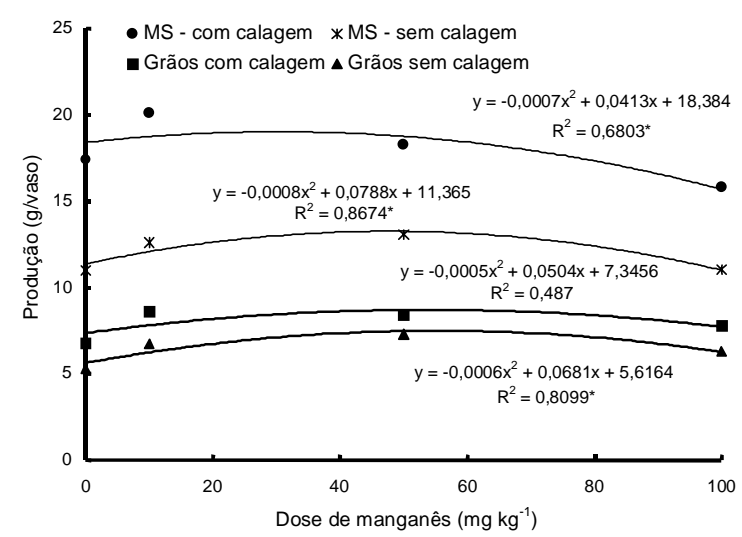

FIG. 1. Produção de matéria seca (MS) e grãos de soja, de acordo com a dose de manganês aplicada na presença e ausência de calagem.

Pesq. agropec. bras., Brasília, v.35, n.8, p.1629-1636, ago. 2000 
deficiência nos tratamentos. Johnson \& Gascho (1989) relatam que a deficiência de Mn mais freqüente, em soja, se relaciona com o $\mathrm{pH}$, tipo de solo e teor de matéria orgânica. Sparrow \& Uren (1987) encontraram uma redução significativa nos teores de $\mathrm{Mn}$ com o aumento de $\mathrm{pH}$ de 4,0 para 5,9, valores, estes, próximos aos encontrados no experimento. Novais et al. (1989) relataram que sintomas de deficiência de $\mathrm{Mn}$ foram reduzidos drasticamente quando o $\mathrm{pH}$ do solo foi reduzido de 6,7 para 5,9.

No tratamento sem calcário, a aplicação da dose de $100 \mathrm{mg} \mathrm{kg}^{-1}$ provocou os primeiros sintomas de toxidez de manganês em estádio V2-3. Com aplicação de calcário, esses sintomas só ocorreram em estádio V3-4. Verificou-se que a soja apresentou um enrugamento do tecido internerval, com clorose generalizada e pontos necróticos espalhados pelo limbo e ao longo dos vasos condutores, tanto na página inferior como superior das folhas e na haste, o que está de acordo com a descrição apresentada por Malavolta (1980), Hannam \& Ohki (1988) e Tanaka et al. (1993). Observou-se, também, uma acentuada redução no crescimento e na produção de matéria seca e de grãos, principalmente no tratamento sem calcário. Shuman \& Anderson (1974) observaram em alguns solos com pH 4,8, nos tratamentos cuja dose aplicada foi de $25 \mathrm{mg} \mathrm{kg}^{-1}$, severos sintomas de toxidez em soja, dose esta dentro da resposta obtida em soja neste experimento. Houve um incremento na produção de vagens nas doses de 10 até $100 \mathrm{mg} \mathrm{kg}^{-1}$ de Mn em relação à testemunha; contudo, não houve diferença estatisticamente significativa $(\mathrm{P}<0,05)$ entre a testemunha e a dose máxima de $100 \mathrm{mg} \mathrm{L}^{-1}$ (Tabela 1). No tratamento adicional, a aplicação do Mn via foliar proporcionou um aumento significativo na produção de vagens e matéria seca total, em ambas as doses de calcário. Este tratamento não apresentou diferença significativa $(\mathrm{P}<0,05)$, em comparação com a dose adequada de Mn aplicada via solo.

$\mathrm{O}$ teor de $\mathrm{Mn}$ nas folhas aumentou com as doses de Mn e diminuiu com a adição de calcário, o que mostra que a análise das folhas discriminou o efeito da correção da acidez do solo (Fig. 3). Na testemunha com aplicação de calcário, foram encontrados os menores teores de $\mathrm{Mn}\left(84 \mathrm{mg} \mathrm{kg}^{-1}\right)$. As maiores produções estiveram associadas aos teores de $\mathrm{Mn}$ nas folhas, na faixa de 150 a $350 \mathrm{mg} \mathrm{kg}^{-1} \mathrm{de} \mathrm{Mn}$, e as menores produções ocorreram quando os teores foliares, considerados tóxicos, estiveram entre 1.155 e $2.380 \mathrm{mg} \mathrm{kg}^{-1} \mathrm{de}$ Mn. Rosolem et al. (1992) consi-
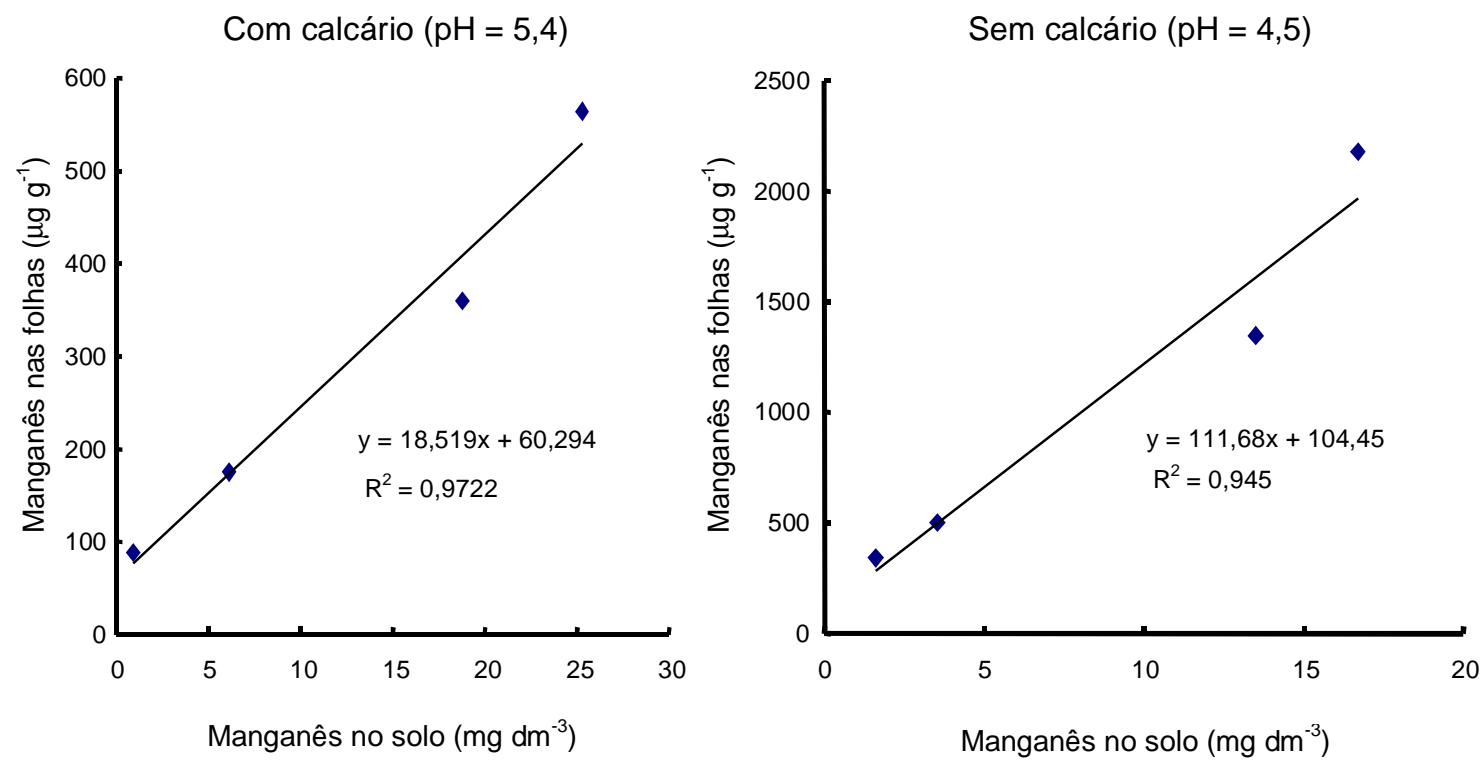

FIG. 2. Relação entre os teores de manganês no solo e nas folhas coletadas em estádio V8-9 (R3-4), para diagnose foliar nas doses 0 e 2,7 t ha ${ }^{-1}$ de calcário, $\mathrm{pH}=4,5 \mathrm{e} \mathrm{pH}=5,4$, respectivamente. 
deraram teores de $90 \mathrm{mg} \mathrm{kg}^{-1}$ nas folhas prejudiciais à produção de matéria seca. Os teores encontrados estiveram entre 31,5 a 2.122,5 $\mathrm{mg} \mathrm{kg}^{-1}$ no caule, de 84 a $1.177,5 \mathrm{mg} \mathrm{kg}^{-1}$ nas folhas, de 60,8 a $1.055 \mathrm{mg} \mathrm{kg}^{-1}$ nas vagens, e de 23,3 a $47 \mathrm{mg} \mathrm{kg}^{-1}$ nos grãos. Esses valores estão muito acima dos teores considerados como nível crítico, de 10 a $20 \mathrm{mg} \mathrm{kg}^{-1}$ encontrados na literatura, para que ocorram sintomas de deficiência. Tanaka et al. (1989) citam teores de 13 e $9 \mathrm{mg} \mathrm{kg}^{-1}$ em folhas de soja com sintomas de deficiência. De acordo com Rosolem et al. (1992), teores na faixa de 11 a $22 \mathrm{mg} \mathrm{kg}^{-1}$ são considerados como níveis de deficiência de Mn em folhas de soja, e como níveis tóxicos, teores na faixa de 140 e $300 \mathrm{mg} \mathrm{kg}^{-1}$. Hannam \& Ohki (1988) citam como nível crítico, para que ocorram sintomas de deficiência, teores em folhas de soja em estádio tanto vegetativo quanto em pleno florescimento, quanto à produção de matéria seca, de $10 \mathrm{mg} \mathrm{kg}^{-1}$ de $\mathrm{Mn}$; quando o parâmetro é a produção de grãos, esses teores sobem para 17 a $22 \mathrm{mg} \mathrm{kg}^{-1}$. São considerados prejudiciais, em folhas com sintomas de toxidez, teores de $529 \mathrm{mg} \mathrm{kg}^{-1}$, e, em folhas com 30 dias, teores que variaram de acordo com a folha coletada, de 100 a $250 \mathrm{mg} \mathrm{kg}^{-1}$. Os teores observados neste experimento são considerados suficientes e chegando, em alguns casos, a se apresentarem bem acima dos níveis tóxicos discutidos. Nas folhas que apresentaram sintomas de toxidez, os valores encontrados foram superiores a $600 \mathrm{mg} \mathrm{kg}^{-1}$.

A Fig. 4 mostra a relação entre os teores de Mn e os teores de $\mathrm{P}, \mathrm{K}, \mathrm{Ca}, \mathrm{Mg}, \mathrm{S}, \mathrm{B}, \mathrm{Cu}, \mathrm{Fe}, \mathrm{Zn}$, encontrados nas folhas em estádio V8 (R3). Na dose 0 de calcário, o efeito do Mn sobre outros elementos foi mais evidente do que na dose equivalente a $2,7 \mathrm{t} \mathrm{ha}^{-1}$, e essas interações foram significativas $(\mathrm{P}<0,05) \mathrm{com}$ o P, K, Ca e o Fe. Existe uma interação primária entre o Mn e o Fe, a qual, provavelmente, decorre das interações químicas na interface solo-raiz (Kochian, 1988). Para o mesmo autor, cátions como $\mathrm{Ca}, \mathrm{Mg}$ e Zn podem inibir a absorção de Mn, porém o que foi observado foi um aumento na absorção de Ca, P e K com o aumento da dose de Mn. Borkert (1991) relata um aumento na concentração de Mn quando foi realizada a adubação potássica. Para Rosolem \& Nakagawa (1990), o K pode causar um efeito depressivo sobre a absorção de Mn, e, quando associado à calagem, a adubação potássica pode levar à ocorrência de deficiência induzida do elemento. A calagem reduziu as interações entre os elementos, principalmente entre o $\mathrm{P}$ e o $\mathrm{K}$; nesses casos, essas interações desapareceram. A relação entre o Fe e o Mn foi a menos afetada. Malavolta (1980) atribui uma interação do tipo inibição competitiva entre o Mn e o $\mathrm{Fe}$, o que pode ser observado nos resultados apre-
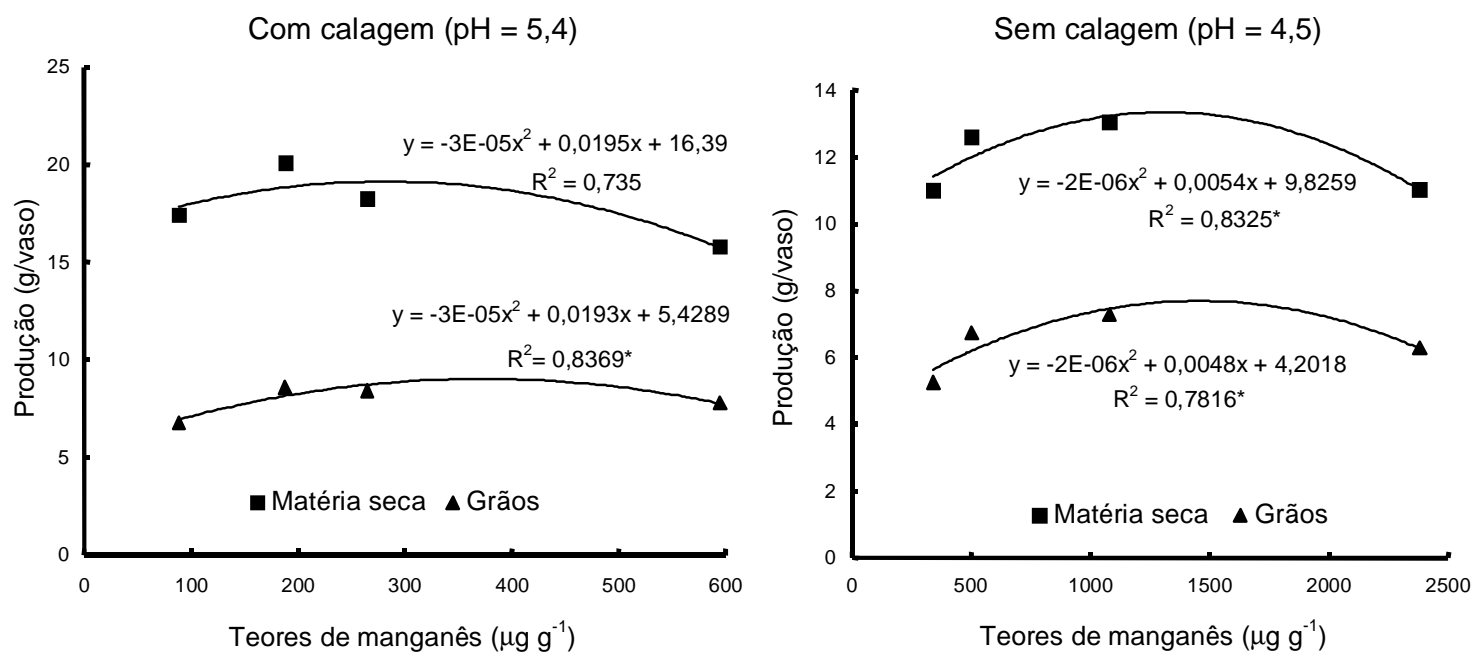

FIG. 3. Produção de matéria seca e grãos de soja, de acordo com os teores de manganês encontrados em folhas coletadas em estádio V8-9 (R3-4) nas doses 0 e 2,7 t ha $^{-1}$ de calcário, $\mathrm{pH}=4,5$ e pH = 5,4, respectivamente. 

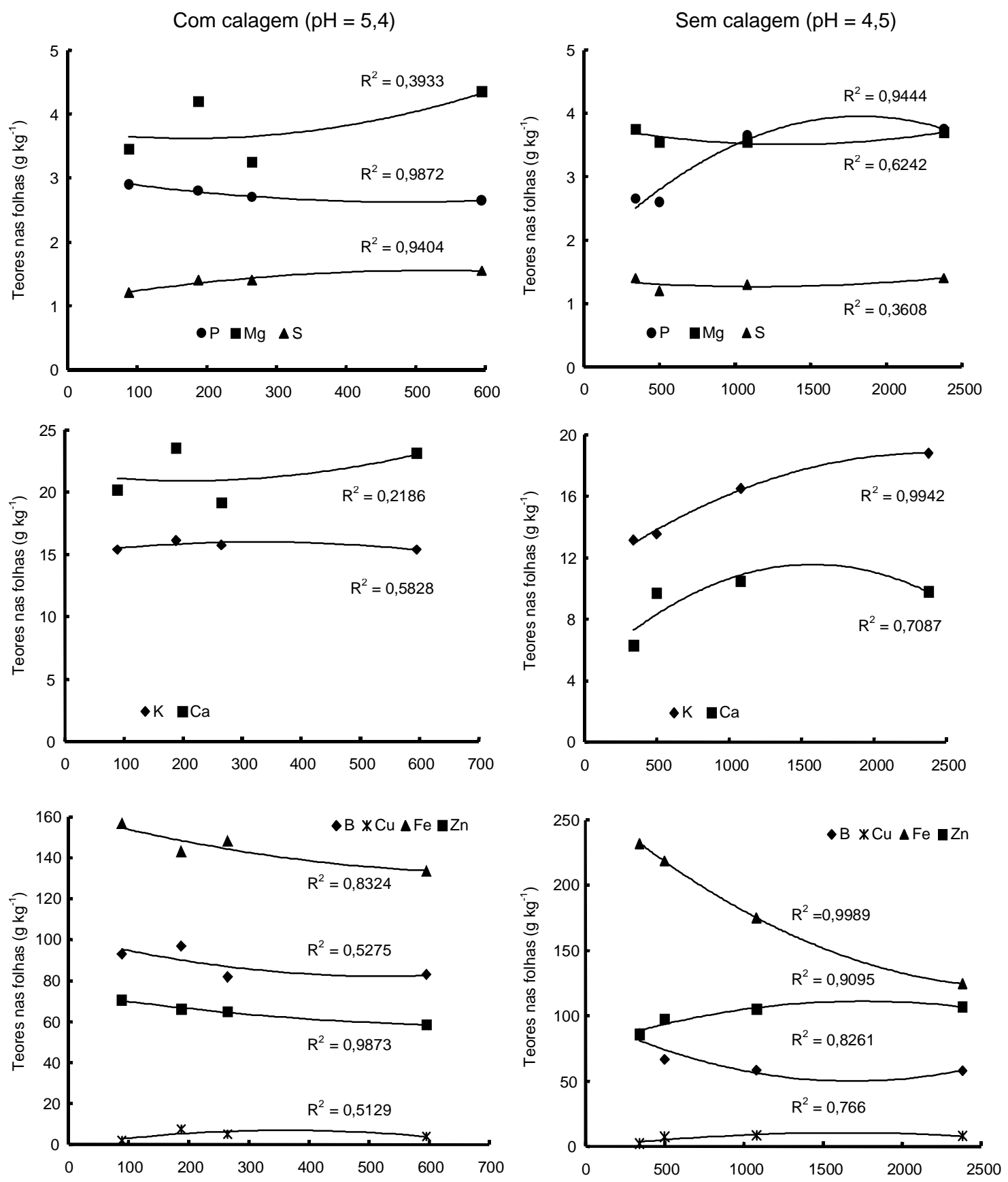

Teores de manganês nas folhas $\left(\mu \mathrm{g} \mathrm{g}^{-1}\right)$

FIG. 4. Relação entre os teores de manganês nas folhas e os teores dos nutrientes $\mathrm{P}, \mathrm{K}, \mathrm{Ca}, \mathrm{Mg}, \mathrm{S}, \mathrm{B}, \mathrm{Cu}, \mathrm{Fe} e$ Zn em folhas coletadas para diagnose foliar (V8-9 (R3-4)) nas doses 0 e 2,7 $\mathrm{t} \mathrm{ha}^{-1}$ de calcário, $\mathrm{pH}=4,5 \mathrm{e}$ pH $=5,4$, respectivamente. 
sentados na Fig. 4. Segundo Zaharieva et al. (1988), as interações entre Fe e Mn ocorrem em dois níveis. No nível de acumulação, o Fe afeta a absorção de Mn; e no nível metabólico, o Mn afeta a atividade do $\mathrm{Fe}$, pela diminuição da concentração desse nutriente, pelo fato de ambos competirem pelo mesmo sítio de absorção. O Mn também é capaz de trocar com o Fe existente nos quelados, fazendo com que diminua sensivelmente a absorção de Fe pelas plantas (Lucena et al., 1988). Nas menores concentrações de Mn, ocorreu um maior acúmulo de $\mathrm{Fe}$, o que corrobora os dados obtidos por Malavolta et al. (1997).

\section{CONCLUSÕES}

1. A calagem reduz a disponibilidade de $\mathrm{Mn}$.

2. A soja responde à aplicação de Mn nas doses de 10 a $100 \mathrm{mg} \mathrm{kg}^{-1}$.

3. A aplicação do Mn via foliar é eficiente em manter a produção de matéria seca e de grãos, em comparação com os melhores tratamentos via solo.

4. A aplicação de $\mathrm{Mn}$ altera o teor de $\mathrm{P}, \mathrm{K}$ e Fe nas folhas, quando o solo não recebe calcário.

\section{AGRADECIMENTOS}

Aos pesquisadores Dr. Roberto Tetsuo Tanaka e Dr. Takashi Muraoka, e a Sra. Marília Ribeiro Garcia Henyei, pela colaboração na realização deste trabalho.

\section{REFERÊNCIAS}

ABREU, C.A.; NOVAIS, R.F.; RAIJ, B. van; RIBEIRO, A.C. Comparação de métodos para avaliar a disponibilidade do manganês em solos. Revista Brasileira de Ciência do Solo, Campinas, v.18, p.81-90, 1994.

ABREU, C.A.; RAIJ, B. van; TANAKA, R.T. Comportamento de cultivares de soja em solo deficiente em Mn. Revista Brasileira de Ciência do Solo, Campinas, v.19, n.1, p.149-152, 1995.

BORKERT, C.M. Manganês. In: FERREIRA, M.E.; CRUZ, M.C.P. (Ed.). Micronutrientes na agricultura. Piracicaba : Potafos/CNPq, 1991. p.173-189.
COSTA, J.A.; MARCHEZAN, E. Características dos estádios de desenvolvimento da soja. Campinas : Fundação Cargill, 1978. 30p.

DECHEN, A.R.; HAAG, H.P; CARMELLO, Q.A.C. Função dos micronutrientes nas plantas. In: FERREIRA, M.E.; CRUZ, M.C.P. (Ed.). Micronutrientes na agricultura. Piracicaba : Potafos/CNPq, 1991. p.65-75.

HANNAM, R.J.; OHKI, K. Detection of manganese deficiency and toxicity in plants. In: GRAHAM, R.D.; HANNAM, R.J.; UREN, N.C. (Ed.). Manganese in soils and plants. Dordrecht : Kluwer Academic, 1988. p.243-260.

JOHNSON, J.; GASCHO, G. Modifying soil and fertilizer chemistry for greater soybean yields. In: THE PHYSIOLOGY, biochemistry, nutrition, and bioengineering of soybeans: implications for future managements. Munson : Foundation for Agronomic Research/Potash \& Phosphate Institute, 1989. p.19-38.

KOCHIAN, L.V. Mechanisms of micronutrient uptake and translocation in plants. In: GRAHAM, R.D.; HANNAM, R.J.; UREN, N.C. (Ed.). Manganese in soils and plants. Dordrecht : Kluwer Academic, 1988. p.229-296.

LUCENA, J.J.; GARATE, A.; CARPENA, O. Theoretical and practical studies on chelate Ca-pH system in solution. Journal of Plant Nutrition, New York, v.11, p.1051-1062, 1988.

MALAVOLTA, E. Elementos de nutrição mineral de plantas. São Paulo : Agronômica Ceres, 1980. 251p.

MALAVOLTA, E.; DAMIÃO FILHO, C.F.; VOLPE, C.A.; MACHADO JÚNIOR, G.R.; VELHO, L.M.S.; ROSA, P.R.F.; LAURENTIZ, S. de. Deficiências e excessos minerais no feijoeiro (Phaseolus vulgaris L., cv. Carioca). Anais da Escola Superior de Agricultura Luiz de Queiroz, Piracicaba, v.37, n.2, p.701-718, 1980.

MALAVOLTA, E.; MALAVOLTA, M.L.; CABRAL, C.P.; MATSUNAGA, E. Nota sobre a deficiência de manganês na mandioca (Manihot esculenta Crantz). Revista de Agricultura, Piracicaba, v.64, n.2, p.107-117, 1989.

MALAVOLTA, E.; VITTI, G.C.; OLIVEIRA, S.A. Avaliação do estado nutricional das plantas: princípios e aplicações. Piracicaba : Potafos, 1997. 319p.

Pesq. agropec. bras., Brasília, v.35, n.8, p.1629-1636, ago. 2000 
NOVAIS, R.F.; NEVES, J.C.L.; BARROS, N.F.; SEDIYAMA, T. Deficiência de Mn em plantas de soja cultivadas em solos de cerrado. Revista Brasileira de Ciência do Solo, Campinas, v.13, p.199-204, 1989.

PIMENTEL-GOMES, F. A estatística moderna na pesquisa agropecuária. Piracicaba : Potafos, 1984. 160p.

ROSOLEM, C.A.; NAKAGAWA, J. Deficiência de Mn em soja, induzida por adubação potássica e calagem. Pesquisa Agropecuária Brasileira, Brasília, v.25, n.6, p.833-836, jun. 1990.

ROSOLEM, C.A.; BESSA, M.A.; AMARAL, P.G. do; PEREIRA, H.F.M. Manganês no solo: sua avaliação e toxidez de manganês em soja. Pesquisa Agropecuária Brasileira, Brasília, v.27, n.2, p.277-285, fev. 1992.

SALCEDO, I.H.; ELLIS, B.G.; LUCAS, R.E. Studies in soil manganese. II. Extractable manganese and plant uptake. Soil Science Society of America. Journal, Madison, v.43, p.138-141, 1979.

SHUMAN, L.M.; ANDERSON, O.E. Evaluation of six extractants for their ability to predict manganese concentrations in wheat and soybeans. Soil Science Society of America. Proceedings, Madison, v.38, p.788-790, 1974.

SIMS, J.T. Soil pH effects on the distribution and plant availability of manganese, copper and zinc. Soil Science Society of America. Journal, Madison, v.50, p.367-373, 1986.
SPARROW, L.A.; UREN, N.C. Oxidation and reduction of $\mathrm{Mn}$ in acidic soils: effect of temperature and soil pH. Soil Biology \& Biochemistry, Oxford, v.19, n.2, p.143-148, 1987.

TANAKA, R.T.; MASCARENHAS, H.A.A. Soja: nutrição, correção do solo e adubação. Campinas : Fundação Cargill, 1992. 60p. (Boletim Técnico, 7).

TANAKA， R.T.; MASCARENHAS, H.A.A.; BORKERT, C.M. Nutrição mineral da soja. In: SIMPÓSIO SOBRE A CULTURA DA SOJA NOS CERRADOS, 1992, Uberaba. Anais. Piracicaba : POTAFOS, 1993. p.105-127.

TANAKA, R.T.; MASCARENHAS, H.A.A.; BULISANI, E.A. Deficiência de manganês em soja induzida por excesso de calcário. Pesquisa Agropecuária Brasileira, Brasília, v.27, n.2, p.247-250, fev. 1992.

TANAKA, R.T.; MASCARENHAS, H.A.A.; MIRANDA, M.A.C.; DEGASPARI, N.; CARMELLO, Q.A. de C. Deficiência nutricional em soja cultivada em solo de cerrado devido à incorporação superficial do calcário. O Agronômico, Campinas, v.41, n.3, p.231-241, 1989.

TISDALE, S.L.; NELSON, L.W.; BEATON, J.D. Micronutrients and other beneficial elements in soils and fertilizers. In: TISDALE, S.L.; NELSON, L.W.; BEATON, J.D. (Ed.). Soil fertility and fertilizers. 4.ed. New York : Macmillan, 1985. p.350-413.

ZAHARIEVA, T.; KASABOV, D.; ROMHELD, V. Responses of peanuts to iron-manganese interaction in calcareous soil. Journal of Plant Nutrition, New York, v.11, p.1015-1024, 1988. 